\title{
GALEAL FLAP BASED ON SUPERFICIAL TEMPORAL VESSELS FOR ORAL CAVITY AND PHARYNX RECONSTRUCTION - AN ANATOMICAL STUDY
}

Fabio Pinto ${ }^{a}$, Roberto Magalhães ${ }^{b}$, Marcelo Durazzo ${ }^{b}$, Lenine Brandão ${ }^{\text {, }}$ Aldo Junqueira Rodrigues Jr.

Pinto F, Magalhães R, Durazzo M, Brandão L, Rodrigues Jr. AJ. Galeal flap based on superficial temporal vessels for oral cavity and pharynx reconstruction - an anatomical study. Clinics. 2008;63(1);97-102.

PURPOSE: Despite the advances in microvascular free tissue transfer for intraoral reconstruction, this surgery is not recommended for all patients. In specific cases, the pedicled temporoparietal galeal flap may be an option for reconstructive procedures in the head and neck regions. The objective of this paper is to present the anatomical aspects of a galeal flap based on the superficial temporal vessels and to test its potential for reconstructing diverse sites of the oral cavity and pharynx.

METHODS: We performed 40 dissections on 34 fresh adult cadavers. The flap vascular anatomy was studied by injecting latex into the superficial temporal vessels. A standardized square-shape flap measuring $10 \mathrm{x} 10 \mathrm{~cm}^{2}$, pedicled on the superficial temporal vessels, was raised. Oral cavity and oropharynx reconstruction simulations were performed after flap transposition into the mouth by passing it under the zygomatic arch. Hypopharyngeal reconstruction was tested by transposing the flap to the neck under the facial nerve.

RESULTS: After latex injection, a rich vascular network over the temporoparietal galea was observed directly from the superficial temporal artery, and a well-vascularized flap based on this vessel was raised. In the reconstruction simulations, the flap was shown to be suitable for the coverage of hypothetical defects in most oral cavity and pharyngeal sites, mainly the retromolar trigone, tonsil area, and buccal mucosa.

CONCLUSIONS: A galeal flap based on the superficial temporal vessels presents favorable anatomical characteristics for oral cavity and pharyngeal reconstruction.

KEYWORDS: Surgical flaps. Mouth. Pharynx. Temporal arteries. Anatomy.

\section{INTRODUCTION}

Oral cavity and pharyngeal reconstructions are widely discussed in the literature. Despite the poor results obtained at the donor site and poor functional outcomes in the reconstructed area, cutaneous and musculocutaneous pedicled flaps continue to be extensively used at some centers. ${ }^{1-3}$

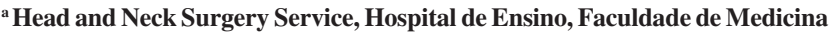
do ABC - São Bernardo do Campo/Brazil.

${ }^{\mathrm{b}}$ Department of Head and Neck Surgery, Hospital das Clínicas, Faculdade de Medicina da Universidade de São Paulo - São Paulo/Brazil.

${ }^{c}$ Department of Topographic Anatomy, Hospital das Clínicas, Faculdade de Medicina da Universidade de São Paulo - São Paulo/Brazil.

pintofr@uol.com.br

Received for publication on September 23, 2007

Accepted for publication on October 26, 2007
Today, free flaps are considered the "state of the art" method for repairing defects of the upper digestive tract resulting from tumor ablation. ${ }^{4}$ However, this technique may not be the best choice in seriously ill or clinically jeopardized patients. Such patients may become subject to serious medical complications when they are submitted to an extended period of anesthesia, commonly associated with the microsurgical reconstructions. ${ }^{5,6}$ Because microsurgery is only performed by very specialized surgeons at advanced centers, free flaps are only available at few institutions that treat head and neck cancers worldwide.

In the past three decades, some authors have attempted to identify new and less complicated methods of surgical reconstruction that use tissues from the cranial region as a 
source of flaps. In 1976, Fox and Edgerton ${ }^{7}$ were the first to employ temporal region fascia to reconstruct the ear. Many of the publications that followed were related to ear and face defects that were repaired using the galeal pedicle flap of the temporoparietal region, also called the temporoparietal fascial flap. ${ }^{8-13}$ Despite the good results that this produced, few authors were interested in using this flap for the reconstruction of mucosal defects of the head and neck. ${ }^{14-16}$

To confirm the hypothesis that the galeal flap, based on superficial temporal vessels, is a viable alternative for oral cavity and pharyngeal reconstruction, we performed 40 cadaveric dissections to study the anatomy of this flap and the feasibility of transferring it to a number of sites in the upper digestive tract.

\section{MATERIAL AND METHODS}

We performed 40 dissections (20 on the right side and 20 on the left) on 34 fresh adult cadavers. In six corpses, the dissections were bilateral. Due to the time restrictions imposed by the pathology department, only one side could be studied in the remaining corpses. The average age of the study group, which was comprised of 23 men and 11 women, was 55.63 years with a standard deviation of 17.03 years. The cephalic perimeter, measured before the dissections, ranged from $53.0 \mathrm{~cm}$ to $60.1 \mathrm{~cm}$ (average of $55.67 \mathrm{~cm}$, standard deviation of $1.87 \mathrm{~cm}$ ).

With the cadaver in the dorsal decubitus position, an incision was performed behind the ear. The auricle was reflected anteriorly and the external auditory canal was cut in order to expose the superficial temporal vessels located in front of the ear. This post-auricular exposure was necessary to preserve the cadaver's appearance within the rules of the necropsy service where this study was conducted.

The superficial temporal artery was dissected and catheterized in front of the auditory canal with a 6 French plastic catheter. Twenty milliliters of red latex (vinyl polymers in water dispersion, manufactured by Suvinil ${ }^{\circledR}$, São Paulo, Brazil) was injected into the artery through the catheter. The same procedure was performed on the superficial temporal vein using blue latex. The galea of the temporoparietal region and its vessels were exposed by subfollicular dissection of the scalp through extension of the previous incision in the coronal plane from one mastoid process to the other (Fig 1).

We analyzed the following factors: the ease of injecting latex into the vessels; the external diameter of the superficial temporal artery and vein in front of the external auditory canal; the number of artery branches over the galea; the relative location of the superficial temporal ves-

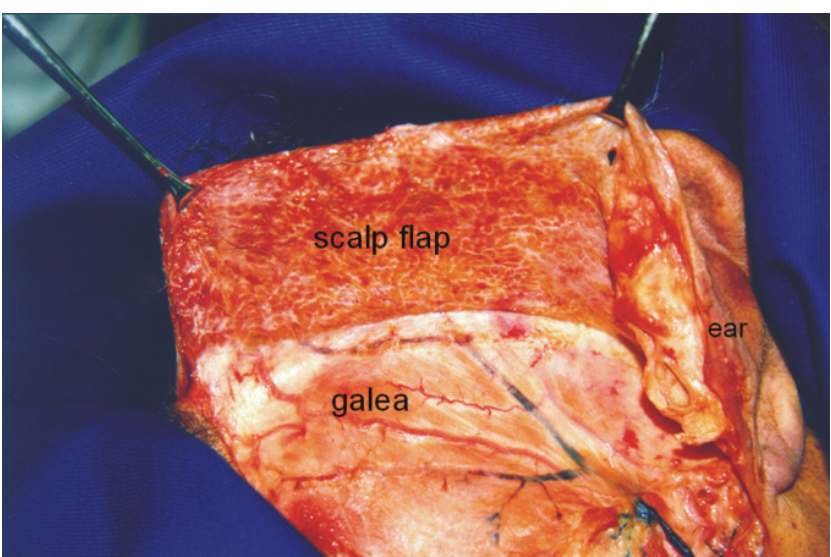

Figure 1 - Subfollicular dissection of the scalp exposing the temporoparietal galea and the superficial temporal vessels filled with latex. The external auditory canal is cut and the ear is reflected anteriorly.

sels and the facial nerve; the distance from the trunk of the superficial temporal artery in front of the ear to its terminal branches over the galea (described here as the maximum distance of the flap pedicle); and the maximum area available for flap constitution based on a quadrangular area of the galea macroscopically vascularized by the superficial temporal vessels. We also tried to observe arterial anastomosis crossing the midline in the bilateral dissections (six cases). A standardized square-shape galeal flap measuring $10 \times 10 \mathrm{~cm}^{2}$, based on the superficial temporal vessels, was raised from the temporoparietal region. The inferior limit of the flap was at the temporal region, $2 \mathrm{~cm}$ above the auditory canal. The dissection of the pedicle flap stopped at the level of the canal (Fig 2). The flap was transposed into the mouth through a tunnel under the zygomatic arch (Fig 3). It was then tested to determine whether it could reach to the following sites: the retromolar trigone, buccal mucosa, floor of the mouth, oral tongue, hard palate, soft palate, tonsil area and posterior wall of oropharynx. The flap was also tested to determine whether it would cover the

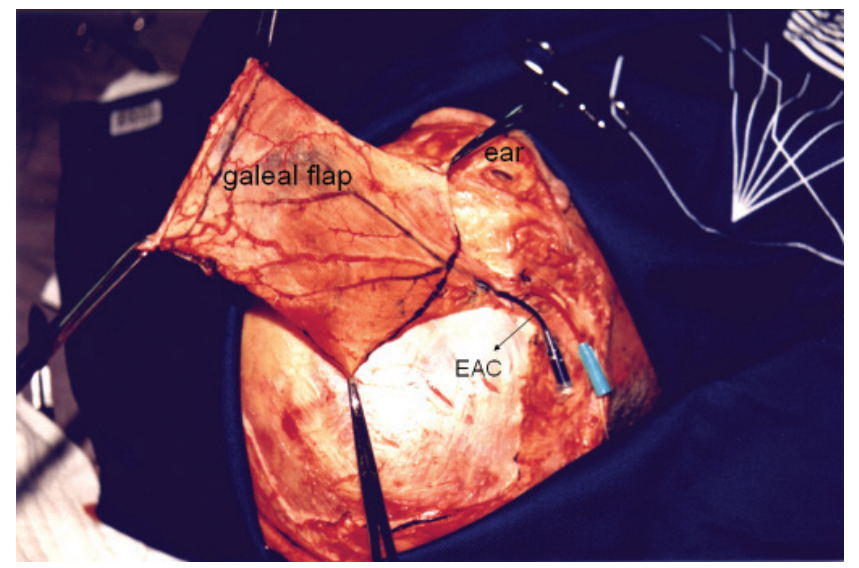

Figure 2 - Galeal flap based on superficial temporal vessels dissected until the level of the external auditory canal (EAC). 


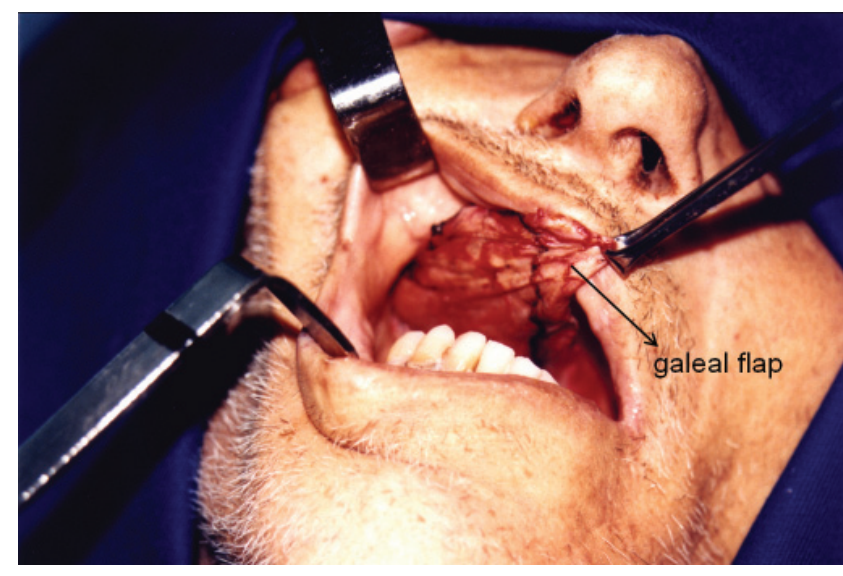

Figure 3 - Galeal flap inside the oral cavity after its transposition through a tunnel under the zygomatic arch.

mucosa of each site entirely or partially. In the last 20 dissections, we tested the possibility of transferring the flap to the neck by passing it under the facial nerve (Fig 4). Lesions to the nerve and its branches were recorded as well as the flap reaching the anatomical position of the thyroid and cricoid cartilages.

The results were compared by sex, dissected side, and cephalic perimeter. Continuous variables were represented as averages and standard deviations. When comparing two continuous variables, the Student's t test was used; for comparisons of two categorical variables, we employed the Cochran's linear trend test, and when only two categories were possible for both variables, for instance sex (male or female) and flap reaching the cricoid ("yes" or "no"), the Pearson chi-squared test was used. Statistical significance was considered when $p<0.05$.

\section{RESULTS}

The superficial temporal vessels were observed in front of the external auditory canal in all dissections. The vessels were deep compared to the facial nerve and their main divisions and relative positioning occurred below the external auditory canal in all cases. No relationship was observed between the flap pedicle and the facial nerve above the external auditory canal. No difficulty was observed during latex injection into the vessels. The external diameter of the artery varied from 2 to $5 \mathrm{~mm}$ (average $=3.24 \mathrm{~mm}$; standard deviation $=0.62 \mathrm{~mm}$ ). The external diameter of

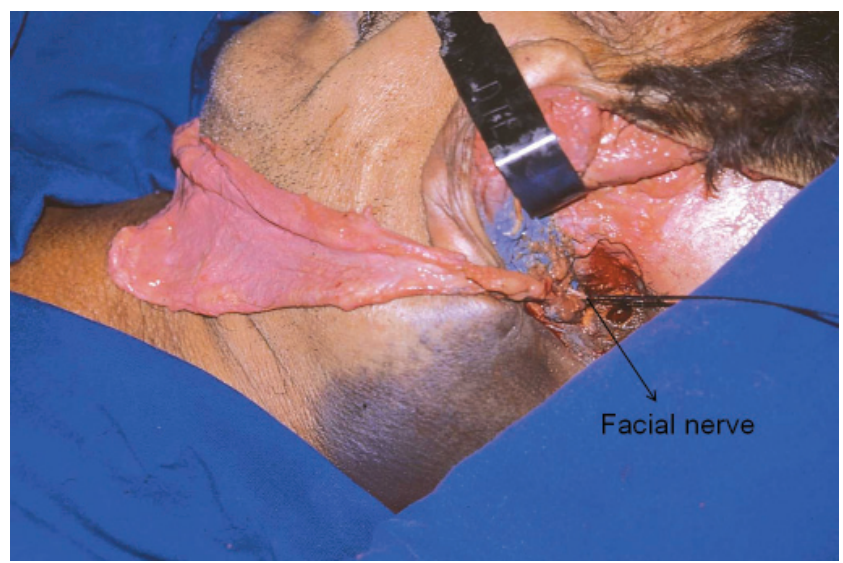

Figure 4 - Galeal flap transposed to the neck under the facial nerve.

the vein varied from 2 to $4 \mathrm{~mm}$ (average $=2.82 \pm 0.51$ $\mathrm{mm}$ ). Two or three branches (average $=2.17 \pm 0.38$ branches) were observed directly off the main trunk of the superficial temporal artery, and these were called the primary branches. Eight to 32 secondary branches (average $=13.58 \pm 5.01$ branches) were observed arising from these primary branches. Arterial anastomosis crossing the midline was observed in all bilateral dissections. The maximum distance of the flap pedicle ranged from 12.2 to $19.8 \mathrm{~cm}$ (average $=15.81 \pm 1.8 \mathrm{~cm}$ ). The maximum area available for flap confection ranged from 100 to $242.82 \mathrm{~cm}^{2}$ (average $=150.63 \pm 34.33 \mathrm{~cm}^{2}$ ).

In all dissections, the harvested flap was thin and pliable. The results of the flap reach position and its coverage for each site in the oral cavity and oropharynx are shown in Tables 1 and 2. The retromolar trigone, buccal mucosa and tonsil areas achieved $100 \%, 87.5 \%$ and $100 \%$ of complete coverage, respectively. The flap reached the posterior wall of the oropharynx in $52.5 \%$ of the cases and covered this site entirely in only four (10\%) cases. When hypopharyngeal reconstruction was simulated, flap rotation to the neck was possible in the 20 cases tested, reaching the anatomical position of thyroid and cricoid cartilages in $100 \%$ and $60 \%$ of the cadavers, respectively. In one case (5\%), a lesion of the frontal branch of the facial nerve was observed.

The superficial temporal artery diameter was larger in male cadavers $(3.48 \pm 0.50 \mathrm{~mm}$ versus $2.69 \pm 0.53 \mathrm{~mm}$; $<0.0001)$. No other statistical relationship was found in this study.

Table 1 - Galeal flap reaching the oral cavity and oropharyngeal sites. $\mathrm{N}=40$

\begin{tabular}{|c|c|c|c|c|c|c|c|c|}
\hline SITE & $\begin{array}{l}\text { Retromolar } \\
\text { trigone }\end{array}$ & $\begin{array}{l}\text { Buccal } \\
\text { mucosa }\end{array}$ & Hard palate & Floor of mouth & Oral tongue & Tonsil area & Soft palate & Posterior wall \\
\hline REACH & $40(100 \%)$ & $40(100 \%)$ & $40(100 \%)$ & $39(97.5 \%)$ & $39(97.5 \%)$ & $40(100 \%)$ & $39(97.5 \%)$ & $21(52.5 \%)$ \\
\hline
\end{tabular}


Table 2 - Galeal flap covering (partial or complete) among oral cavity and oropharyngeal sites. Best results achieved in retromolar trigone, buccal mucosa and tonsil area (bold). $\mathrm{N}=40$

\begin{tabular}{|c|c|c|c|c|c|c|c|c|}
\hline \multirow[b]{2}{*}{ Covering } & \multicolumn{8}{|c|}{ SITE } \\
\hline & $\begin{array}{l}\text { Retromolar } \\
\text { trigone }\end{array}$ & $\begin{array}{l}\text { Buccal } \\
\text { mucosa }\end{array}$ & Hard palate & Floor of mouth & Oral tongue & Tonsil area & Soft palate & Posterior wall \\
\hline No cover* & - & - & - & $1(2.5 \%)$ & $1(2.5 \%)$ & - & $1(2.5 \%)$ & $19(47.5 \%)$ \\
\hline Partial & - & $5(12.5 \%)$ & $28(70 \%)$ & $18(45 \%)$ & $32(80 \%)$ & - & $21(52,5 \%)$ & $17(42,5 \%)$ \\
\hline Complete & $40(100 \%)$ & $35(87.5 \%)$ & $12(30 \%)$ & $21(52.5 \%)$ & $7(17.5 \%)$ & $40(100 \%)$ & $18(45 \%)$ & $4(10 \%)$ \\
\hline Total & $40(100 \%)$ & $40(100 \%)$ & $40(100 \%)$ & $40(100 \%)$ & $40(100 \%)$ & $40(100 \%)$ & $40(100 \%)$ & $40(100 \%)$ \\
\hline
\end{tabular}

* The item NO COVER corresponds to the situations in which the flap did not reach the region under study. The results are presented in number of cases and percentage.

\section{DISCUSSION}

Many authors have used the temporoparietal galeal flap to repair defects of the ear, ${ }^{13,17}$ face, ${ }^{18}$ and extremities. ${ }^{19} \mathrm{Al}-$ though the viability of galeal flaps is well demonstrated in anatomical and clinical studies, ${ }^{20-22}$ few reports in the literature have examined the use of this kind of flap in the reconstruction of head and neck mucosal defects. ${ }^{14-16}$ This paper not only analyzes the anatomy of the galeal flap based on superficial temporal vessels, but also details the technique required to employ this flap in reconstructive surgery of the oral cavity and pharynx.

The first finding in this study was the lack of difficulty in filling the superficial temporal vessels with latex, which indicates a low obstruction rate of the pedicle vessels using this method. The average external diameter of the superficial temporal vessels exceeded $2.8 \mathrm{~mm}$, which allowed for easy dissection in all cases. Even in women, whose artery diameter was significantly smaller, there was no difficulty in finding the vascular pedicle. These results, combined with their constant position (always in front of the external auditory canal), demonstrate that the superficial temporal artery and vein present good anatomical characteristics for use as a vascular pedicle of flaps. Another anatomical constant was the position of the pedicle relative to the facial nerve. The vessels were observed deeper than the nerve trunk and their main divisions and the relative position were found below the external acoustic meatus in all dissections. No relationship between the superficial temporal vessels and the nerve trunk was observed above the external auditory canal. This anatomical finding is important because if the plane of external auditory canal is respected during galeal flap raising, no facial nerve injury would occur throughout flap mobilization.

From the superficial temporal artery, two or three primary branches and eight to 32 secondary branches (average of 13.58 secondary branches) were observed. These secondary branches generate a rich vascular network over the galea, which delimits temporoparietal galeal flaps with an average area of $150.63 \mathrm{~cm}^{2}$. Our findings corroborate those of some researchers that point to the feasibility of obtaining large galeal flaps based on superficial temporal vessels..$^{20,23}$ The maximum distance of the flap pedicle, measured from the artery trunk in front of the auditory canal to artery's terminal branches over the galea, had an average value of $15.81 \mathrm{~cm}$. This measurement is similar to findings by Har-Shai et al. ${ }^{23}$ and confers a satisfactory rotation arc to the flap.

The adequacy of pedicle length becomes evident when the results of flap reach and coverage are analyzed. The galeal flap reached most of the oral cavity and oropharynx sites in more than $97 \%$ of cases. The best results were achieved in the retromolar trigone, the tonsil area, and the buccal mucosa (reaching 100\% of these three sites and completely covering $100 \%, 100 \%$ and $87.5 \%$ of them, respectively), suggesting that the temporoparietal galeal flap may be a good option for the repair of defects in these regions after extensive cancer resections. The poor results obtained in the posterior wall of the oropharynx should discourage the use of the galeal flap as the first choice for reconstructing this area.

In the reconstruction simulation of the hypopharynx, it was noted that flap transposition to the neck is anatomically feasible despite the morbidity associated with facial nerve manipulation. A low facial nerve branch lesion rate (5\%) was observed during flap rotation to the neck. The flap's extension to the anatomical position of thyroid cartilage $(100 \%)$ was greater than for cricoid cartilage $(60 \%)$. The anatomical position of thyroid cartilage corresponds to the lateral aspect of the hypopharynx, particularly the piriform sinus mucosa. The level of cricoid cartilage is similar to the hypopharynx's post-cricoid area and the cricopharyngeal muscle. These results suggest that the upper defects in the hypopharynx, mainly those resulting from a pharyngolaryngectomy for piriform sinus cancer, are more suitable for repair by this flap than lower defects close to 
the cervical esophagus.

An important pitfall of the temporoparietal galeal flap technique is galea exposition by a subfollicular dissection of the scalp flap. Researchers in this study, as with others, had difficulty with exposure of the temporoparietal galea. ${ }^{10,18,19}$ This may be a result of the fact that there was no surgical plane between the galea and the skin. A tedious dissection is required to preserve the superficial temporal vessels, as well as the hair follicles. The lesion of some follicles may lead to alopecia at the donor site, one of the potential complications of galeal flap use. However, this complication is infrequent according to the literature and is usually transient when it does occur. ${ }^{13,14,19,24,25}$

Extensive mucosal head and neck cancer resections commonly lead to huge openings between the upper digestive tract and the neck. One of the most important objectives of the reconstruction procedures is to seal these openings to enable re-establishment of the patient's deglutition. The galeal flap, based on superficial temporal vessels, may be a good option for this purpose since it is a well-vascularized tissue near the site of the defects. In a clinical situation, the flap may be quickly raised by a pre-auricular approach with temporal extension, which generally results in an inconspicuous scar, as observed by other researchers. ${ }^{13,14,22}$ Here, the post-auricular exposure was employed only because of the necropsy service's rule against disturbing the appearance of cadavers. For the same reason, the zygomatic arch was not excised to test the additional reach of the flaps. Similar to studies performed by Panje and
Morris ${ }^{14}$ our results of the flap transposition method to the mouth under the zygomatic arch are encouraging.

The pliability and thinness of this flap make it adaptable to the reconstruction of mucosal defects for which bulky flaps are unnecessary. These characteristics make the galeal flap resemble other thin free flaps, such as the forearm flap. However, this procedure is advantageous because microvascular surgery is not required, since it uses a pedicled flap. The pedicled temporoparietal galeal flap may be the first choice for repairing posterior oral cavity and lateral oropharynx defects (resulting, for instance, from a composite resection for retromolar trigone carcinoma), especially when the surgical time associated with microvascular procedures needs to be shortened, as occurs when treating jeopardized or seriously ill patients. Another potential first choice indication would occur when the patient does not have good recipient vessels for a microvascular flap due to previous neck dissection or radiotherapy, which is a frequent condition in clinical practice. However, when a bulky flap is necessary, as in subtotal glossectomies, the galeal flap is not a good choice.

Finally, the low number of significant statistical relationships obtained in this study suggests that the success of an eventual upper digestive tract reconstruction using this flap is barely influenced by sex, cephalic diameter or side of operation. In conclusion, a galeal flap based on superficial temporal vessels presents favorable anatomical characteristics for oral cavity and pharynx reconstruction.

\section{REFERENCES}

1. Andrews BT, McCulloch TM, Funk GF, Graham SM, Hoffman HT Deltopectoral flap revisited in the microvascular era: a single-institution 10-year experience. Ann Otol Rhinol Laryngol. 2006;115:35-40.

2. Liu R, Gullane P, Brown D, Irish J. Pectoralis major myocutaneous pedicled flap in head and neck reconstruction: retrospective review of indications and results in 244 consecutive cases at Toronto General Hospital. J Otolaryngol. 2001;30:34-40.

3. Vartanian JG, Carvalho AL, Carvalho SM, Mizobe L, Magrin J, Kowalski LP. Pectoralis major and other myofascial/myocutaneous flaps in head and neck cancer reconstruction: experience with 437 cases at a single institution. Head Neck. 2004;26:1018-23.

4. Hurvitz KA, Kobayashi M, Evans GR. Current options in head and neck reconstruction. Plast Reconstr Surg. 2006;118:122e-133e.

5. Shestak KC, Jones NF, Wu W, Johnson JT, Myers EN. Effect of advanced age and medical disease on the outcome of microvascular reconstruction for head and neck defects. Head Neck. 1992;14:14-8.

6. Ozkan O, Ozgentas HE, Islamoglu K, Boztug N, Bigat Z, Dikici MB. Experiences with microsurgical tissue transfers in eldery patients. Microsurgery. 2005;25:390-5.
7. Fox JW, Edgerton MT. The fan flap: an adjunct to ear reconstruction. Plast Reconstr Surg. 1976;58:663-7.

8. Avelar JM, Psillakis JM. The use of galea flaps in craniofacial deformities. Ann Plast Surg. 1981;6:464-9.

9. Horowitz JH, Persing JA, Nichter L S, Morgan RF, Edgerton MT. Galealpericranial flaps in head and neck reconstruction - anatomy and application. Am J Surg. 1984;148:489-97.

10. Cheney ML, Varvares MA, Nadol Jr. JB. The temporoparietal fascial flap in head and neck reconstruction. Arch Otolaryngol Head Neck Surg. 1993;119:618-23.

11. Brent B, Byrd HS. Secondary ear reconstruction with cartilage grafts covered by axial, random, and free flaps of temporoparietal fascia. Plast Reconstr Surg. 1983;72:141-51.

12. Ellis DS, Toth BA, Stewart WB. Temporoparietal fascial flap for orbital and eyelid reconstruction. Plast Reconstr Surg. 1992;89:606-12.

13. Park C, Lew DH, Yoo W. M. An analysis of 123 temporoparietal fascial flaps: anatomic and clinical considerations in total auricular reconstruction. Plast Reconstr Surg. 1999;104:1295-1306. 
14. Panje WR, Morris, MR. The temporoparietal fascia flap in head and neck reconstruction. Ear Nose Throat J. 1991;70:311-7.

15. Beeby MPB, Artigot JLP, Zuloaga AA. Vascularised temporoparietal fascial flap for closure of an orocutaneous fistula. Br J Plast Surg. 2001;54:275-6.

16. Nayak VK, Deschier DG. Pedicled temporoparietal fascial flap reconstruction of select intraoral defects. Laryngoscope. 2004;114:1545-8.

17. Cotlar SW. Reconstruction of the burned ear using a temporalis fascial flap. Plast Reconstr Surg. 1983;71:45-8.

18. Dolan R. Resurfacing extensive malar and preauricular cutaneous defects with pedicled temporoparietal fascia. Dermatol Surg. 2000;26:949-54

19. Brent B, Upton J, Acland RD, Shaw WW, Finseth FJ, Rogers C, et al. Experience with the temporoparietal fascial free flap. Plast Reconstr Surg. 1985;76:177-88.
20. Abdul-Hassan HS, Ascher GD, Acland, RD. Surgical anatomy and blood supply of the fascial layers of the temporal region. Plast Reconstr Surg. 1986;77:17-24.

21. Magalhães RP, Ferraz AR, Brandão LG, Magalhães MG. Osteogaleal pedicle flap of the occipital region for head and neck reconstruction an anatomic study. J Otolaryngol. 1998;27:195-9.

22. Rose EH, Norris MS. The versatile temporoparietal fascial flap: adaptability to a variety of composite defects. Plast Reconstr Surg. 1990;85:224-32.

23. Har-Shai Y, Fukuta K, Collares MV, Stefanovic PD, Filipovic BR, Herschman BR, et al. The vascular anatomy of the galeal flap in the interparietal and midline regions. Plast Reconstr Surg. 1992;89:64-9.

24. Byrd HS. The use of subcutaneous axial fascial flaps in reconstruction of the head. Ann Plast Surg. 1980;4:191-8.

25. Smith RA. The free fascial scalp flap. Plast Reconstr Surg. 1980;66:2049. 